\title{
Observed Interactions Among Haze, Fog and Atmospheric Boundary Layer during a Haze-fog Episode in the Yangtze River Delta Region, Eastern China
}

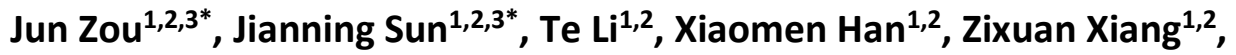 \\ Jie Sha ${ }^{1,2}$ \\ ${ }^{1}$ Joint International Research Laboratory of Atmospheric and Earth System Sciences, Nanjing \\ University, Nanjing, China \\ ${ }^{2}$ School of Atmospheric Sciences, Nanjing University, Nanjing, China \\ ${ }^{3}$ Collaborative Innovation Center of Climate Change, Jiangsu Province, China
}

\section{ABSTRACT}

A severe haze-fog episode occurred in the Yangtze River Delta region of eastern China during 22-30 November, 2018. In this period, the $\mathrm{PM}_{2.5}$ mass concentration and meteorological parameters at the surface were collected at the Station for Observing Regional Processes of the Earth System site in Nanjing. The vertical distributions of $\mathrm{PM}_{2.5}$, humidity and potential temperature below $500 \mathrm{~m}$ were observed simultaneously by an unmanned aerial vehicle, and the profile of potential temperature at 1400 local standard time on each day was also observed by radiosonde at the same site. During the first four days, the $\mathrm{PM}_{2.5}$ mass concentration increased, the maximum convective planetary boundary layer height $(\mathrm{CBLH})$ decreased, and the air humidity increased. These are favorable conditions for fog formation. In the latter five days, fog formed on four days, with a lowering of the $\mathrm{CBLH}$ and a further increase in $\mathrm{PM}_{2.5}$ mass concentration. We found that the fog top cooling induced a potential temperature jump (i.e., sharp increase of potential temperature) with much warmer temperatures above the cloud top cooling and that this particular thermal structure was maintained until the end of the fog period, which significantly suppressed the daytime development of the planetary boundary layer after fog dissipation. The fog-induced reduction of the CBLH further increased the $\mathrm{PM}_{2.5}$ mass concentration. We also found that the wet deposition of fog on $\mathrm{PM}_{2.5}$ was negligible. The scavenging effect of fog on aerosols only acts during a fog period. When the fog dissipates, the aerosols are liberated from the fog droplets to the atmosphere.

* Corresponding Authors:

Jun Zou

junzou@nju.edu.cn

Jianning Sun

jnsun@nju.edu.cn

Keywords: Haze-fog episode, Potential temperature jump, Planetary boundary layer height, $\mathrm{PM}_{2.5}$

\section{Publisher:}

Taiwan Association for Aerosol Research

ISSN: $1680-8584$ print

ISSN: 2071-1409 online

\section{Copyright: The Author(s).}

This is an open access article distributed under the terms of the Creative Commons Attribution License (CC BY 4.0), which permits unrestricted use, distribution, and reproduction in any medium, provided the original author and source are cited.

\section{INTRODUCTION}

Because of the increasing energy consumption associated with rapid urbanization and industrialization, many regions of China, especially megacities and city clusters in coastal eastern China, have experienced high levels of air pollution (He et al., 2002; Chan and Yao, 2008; Tie and Cao, 2009; He et al., 2013; Ding et al., 2016a; Zhao et al., 2018; Barkjohn et al., 2020). In these regions, fine particular matter $\left(\mathrm{PM}_{2.5}\right.$; particles with an aerodynamic diameter of 2.5 microns or lower in ambient air) often attains extremely high concentrations during the winter haze period (Ding et al. 2013a; Huang et al., 2014; Guo et al., 2014; Zhang et al., 2014; Chen et al., 2017; Ma et al., 2017; Liu et al., 2019). High levels of air pollution can significantly modify the weather by changing air temperature, cloud conditions, and even precipitation (Banta et al., 1998, Fiore et al., 2002, Ding et al., 2013b, Huang et al., 2016, Karle et al., 2020). The increase in atmospheric 
aerosols over China has been shown to heat the atmosphere and generate a cyclonic circulation anomaly that weakens the East Asian winter monsoon (Niu et al., 2010a). The weakened East Asian winter monsoon circulation results in less cold and dry air being transported to the region and favors the formation of haze and fog over eastern China (Niu et al., 2010a; Zhang et al., 2014).

The high $\mathrm{PM}_{2.5}$ levels reduce surface air temperature by blocking the solar radiation and increase air temperature in the upper convective planetary boundary layer (CBL) by the heating effect of absorbing aerosols, leading to a stabilized CBL. The enhanced CBL stability suppresses the vertical mixing and dispersion of air pollutants, resulting in higher $\mathrm{PM}_{2.5}$ concentrations (Wang et al., 2014; Gao et al., 2015). The scattering and absorbing effects of aerosols can reduce the surface heat flux, leading to a decrease of $C B L$ height (CBLH) and consequently an increase of $\mathrm{PM}_{2.5}$ concentrations during the daytime (Zou et al., 2017). The aerosols might also decrease surface nocturnal cooling (similar to clouds), and it is possible that nighttime stability would not be as strong as under cleaner conditions (VanReken et al., 2017). Ding et al. (2016b) demonstrated that black carbon (BC) aerosols induce heating in the $C B L$, particularly in the upper CBL, and that the resulting stabilized stratification and decreased surface heat flux substantially depress the development of the $\mathrm{CBL}$ and consequently enhance the occurrences of extreme haze pollution episodes. They defined this process as "dome effect" of BC and suggested reducing BC emissions as an efficient way to mitigate the extreme haze pollution in megacities of China.

Due to heterogeneous nucleation, aerosols can promote fog formation (Sachweh and Koepke, 1995; Mohan and Payra, 2009) to such an extent that supersaturation or saturation is not needed for the fog to form (Kulmala et al., 1997). Therefore, in moist areas, high levels of air pollution often induce more fog events. Observations have shown that the frequencies of fog events in wintertime over eastern-central China have doubled over the past three decades (Niu et al., 2010a). In the Central Valley of California, observations have shown that the frequency of fog events increased by 85\% from 1930 to 1970 because of increased air pollution (Gray et al., 2019).

The Yangtze River Delta (YRD), with Shanghai at its center, is a triangle-shaped megalopolis comprising 26 cities in Jiangsu, Zhejiang, and Anhui province. The YRD region is a flat topography. It is one of the most economically developed and densely populated areas in China. It is also one of the high fog occurrence regions in China (Niu et al., 2010b). Advection fog, which forms when warm, moist air from the East China Sea comes across the region, is common in the YRD (Shi et al., 2010; Lin et al., 2017). Ding et al. (2019) found that BC plays an important role in advectionradiation fog formation in the YRD region by inducing a mesoscale cyclonic wind anomaly that can transport moist air from the sea into this region and help form heavy fog at night.

Fog water can provide a medium for aqueous phase reactions and transform primary pollutants into secondary aerosols (Graedel et al., 1985; Dall'Osto et al., 2009). The wet scavenging effect of fog can also significantly reduce the aerosol concentration in the atmosphere (Niu et al., 2010b; Han et al., 2018). Clarifying the relationship between fog and aerosols is crucial for understanding the formation and evolution of both haze and fog episodes, which are associated with CBL processes (Ding et al., 2019). However, the interactions among haze, fog, and CBL have rarely been reported in the YRD. During 22-30 November, 2018, the YRD region suffered a severe haze-fog episode with a high $\mathrm{PM}_{2.5}$ mass concentration and multi-day fog occurrences. In this study, we focused on the interactions among haze, fog, and CBL processes based on observations during this period.

\section{OBSERVATION AND DATA PROCESSING}

During the severe haze - fog event that occurred during 22-30 November, 2018, in the YRD region, $\mathrm{PM}_{2.5}$ mass concentration, solar radiation, surface heat flux, and meteorological data (including wind, temperature, humidity, and precipitation) were collected at the Station for Observing Regional Processes of the Earth System (SORPES) site (32 $\left.7^{\prime} 14^{\prime \prime} \mathrm{N}, 118^{\circ} 57^{\prime} 10^{\prime \prime} \mathrm{E}\right)$ in Nanjing (Ding et al., 2013a, b; Zou et al., 2017). The SORPES station is a cross-disciplinary research and experimentation platform developed by Nanjing University in collaboration with the University of Helsinki. The observation site is located on the Xianlin Campus of Nanjing University, suburban area of Nanjing, approximately $20 \mathrm{~km}$ northeast of downtown Nanjing. The PM 2.5 mass concentration was measured by a mass analyzer (SHARP-5030, Thermo Fisher Scientific, 
Massachusetts, USA), which was housed on the top floor of a laboratory building. The precision of the mass analyzer is $\pm 2 \mu \mathrm{g} \mathrm{m}^{-3}$ below $80 \mu \mathrm{g} \mathrm{m}^{-3}$ and $\pm 5 \mu \mathrm{g} \mathrm{m}^{-3}$ above $80 \mu \mathrm{g} \mathrm{m}^{-3}$. The surface sensible and latent heat fluxes were measured by an eddy covariance system (CSAT 3A, Campbell Scientific, Utah, USA), which was mounted in the observation yard at $2.2 \mathrm{~m}$ above ground level (AGL). The signals for the eddy covariance calculations were sampled at $10 \mathrm{~Hz}$, and the data were subjected to spike detection and rejection algorithms (Zou et al., 2017). The sensible heat flux $(H s)$ was computed at a half-hour interval, which is the widely accepted duration for calculating turbulent fluxes (Nordbo et al., 2013). Corrections were applied for sonic virtual temperature (Schotanus et al., 1983). Solar radiation was measured by a 4-component net radiometer (CNR4, Campbell, USA), which was mounted in the observation yard at $2.6 \mathrm{~m} \mathrm{AGL}$. Wind, temperature, and humidity data were measured by sensors installed at $9 \mathrm{~m} \mathrm{AGL}$ on a $75 \mathrm{~m}$ tower. The measurements were conducted at six levels on this tower: $4,9,18,36,54$, and $72 \mathrm{~m}$. We use the data acquired at $9 \mathrm{~m}$ because this height was closest to the $10 \mathrm{~m}$ WMO standard. Wind speed (WS) and wind direction (WD) were measured by an anemometer, including a 010C wind speed sensor (Campbell, USA) and a 020C wind direction sensor (Campbell, USA). Temperature ( $T$ ), relative humidity $(R H)$ and specific humidity $(q)$ were measured by a HMP155A temperature and relative humidity probe (Campbell, USA). Precipitation was measured by a TE525WS-L rain gage (Campbell, USA) in the observation yard.

To know the maximum CBLH of each day during this haze-fog event, radiosonde measurements were carried out at 1400 local standard time (LST) at the SORPES site. The iMet-4 radiosonde (International Met Systems, USA) was used to acquire the temperature, pressure, humidity and GPS information, and the sounding data were received by a 3050A receiver (International Met Systems, USA). The GPS data were used to calculate the wind speed and direction, assuming that the radiosonde moved with the wind. To obtain the vertical profiles of $\mathrm{PM}_{2.5}$ concentration and the meteorological parameters, measurements were achieved by an unmanned aerial vehicle (UAV). The UAV was an M600 Pro hexacopter (DJI, China). The maximum flight height was $500 \mathrm{~m}$ $A G L$, and the flight time for descending with the payload was 16-18 min (airspeed was about $\left.1 \mathrm{~m} \mathrm{~s}^{-1}\right)$. An iMet-4 radiosonde was mounted on the UAV to measure the air temperature and humidity, and an AM520 PM2.5 sensor (TSI, USA) was used to monitor the $\mathrm{PM}_{2.5}$ concentration. The AM520 PM 2.5 sensor was calibrated before the observation using the mass analyzer (SHARP5030), the difference between these two measurements was less than $5 \mu \mathrm{g} \mathrm{m}^{-3}$. The profiles measured in the ascending process of the UAV were used in this study. The UAV measurement times are listed in Table 1.

The CBLH can be derived from radiosonde data, as well as the UAV observation data (when the $\mathrm{CBLH}$ is below $500 \mathrm{~m}$ ). The radiosonde-derived CBLH reveals a good agreement with other methods, for example, the CBLHs derived from radiosonde and lidar backscatter measurements coincide within $\pm 200 \mathrm{~m}$ (Hennemuth and Lammert, 2006). In this study, when there was no fog, we determined the CBLH as the height at which the vertical gradient of potential temperature had its maximum value (Stull, 1988; Batchvarova and Gryning, 1991) and determined the nighttime planetary boundary layer height (PBLH) as the height of the top of the near-surface inversion layer (Stull, 1988). However, when fog existed, we define the CBLH as the height of the top of the fog layer, above which an elevated inversion or stable layer could be identified or where air moisture decreased significantly (Seibert et al., 2000).

\section{RESULTS AND DISCUSSION}

\subsection{Overview of Observations}

Time series of wind speed and wind direction ( $W S$ and $W D$ ), humidity ( $q$ and $R H$ ), temperature $(T)$ and surface sensible heat flux $(H s)$, solar radiation $(S R), C B L H, \mathrm{PM}_{2.5}$ mass concentration, and precipitation in the haze-fog event of 22-30 November, 2018, are shown in Fig. 1 . The periods of fog occurrence are shaded. A relative humidity value exceeding $90 \%$ was used to distinguish light fog from haze (Schichtel et al., 2001; Doyle and Dorling, 2002). We used this criterion to separate fog from haze and determine the onset time of fog. In the nine days, the WS was often less than $2 \mathrm{~m} \mathrm{~s}^{-1}$ and rarely reached $3 \mathrm{~m} \mathrm{~s}^{-1}$, whereas the $W D$ covered almost all orientations but was mostly northeasterly or southeasterly. Low wind speed is a favorable condition for the formation 
Table 1. UAV measurement times during the fog and haze episode of 22-30 November, 2018. The symbol $x$ denotes the beginning time of each measurement.

\begin{tabular}{|c|c|c|c|c|c|c|c|c|c|}
\hline Time & $11 / 22$ & $11 / 23$ & $11 / 24$ & $11 / 25$ & $11 / 26$ & $11 / 27$ & $11 / 28$ & $11 / 29$ & $11 / 30$ \\
\hline 0800 & $x$ & $x$ & $x$ & $x$ & $x$ & $x$ & $x$ & $x$ & $x$ \\
\hline 0830 & & $x$ & $x$ & $x$ & $x$ & $x$ & $x$ & $x$ & $x$ \\
\hline 0900 & $x$ & $x$ & $x$ & $x$ & $x$ & $x$ & $x$ & $x$ & $x$ \\
\hline 0930 & $x$ & & & & $x$ & & & $x$ & $x$ \\
\hline 1000 & $x$ & & $x$ & $x$ & $x$ & & $x$ & $x$ & \\
\hline 1030 & $x$ & & & $x$ & & $x$ & $x$ & & \\
\hline \multicolumn{10}{|l|}{1100} \\
\hline \multicolumn{10}{|l|}{1130} \\
\hline 1200 & & & & $x$ & & & & & \\
\hline 1230 & & & & $x$ & & & & & \\
\hline 1300 & & & $x$ & $x$ & & & & & $x$ \\
\hline 1330 & & & $x$ & $x$ & & $x$ & $x$ & $x$ & $x$ \\
\hline \multicolumn{10}{|l|}{1400} \\
\hline 1430 & $x$ & $x$ & & & $x$ & & & & \\
\hline 1500 & $x$ & $x$ & & & $x$ & $x$ & & $x$ & $x$ \\
\hline 1530 & & $x$ & & & $x$ & $x$ & & $x$ & $x$ \\
\hline 1600 & & & $x$ & & $x$ & $x$ & & $x$ & $x$ \\
\hline \multicolumn{10}{|l|}{1630} \\
\hline \multicolumn{10}{|l|}{1700} \\
\hline 1730 & $x$ & & & & & & & & \\
\hline 1800 & $x$ & & & & & & & & \\
\hline 1830 & $x$ & & & & $x$ & & & & $x$ \\
\hline 1900 & & $x$ & $x$ & & $x$ & $x$ & & $x$ & $x$ \\
\hline 1930 & $x$ & $x$ & $x$ & & $x$ & $x$ & & $x$ & $x$ \\
\hline 2000 & $x$ & $x$ & $x$ & & $x$ & $x$ & $x$ & $x$ & \\
\hline
\end{tabular}

of haze-fog episodes. The near surface air temperature had diurnal variation between $6^{\circ} \mathrm{C}(279 \mathrm{~K})$ and $20^{\circ} \mathrm{C}(293 \mathrm{~K})$. The minimum temperature at night was not very low.

The first pollution phase of the observation extended from 22 to 26 November (Period 1). The $\mathrm{PM}_{2.5}$ mass concentration increased from $50 \mu \mathrm{g} \mathrm{m}^{-3}$ to approximately $150 \mu \mathrm{g} \mathrm{m}^{-3}$. There was no fog in Period 1, and the $R H$ varied diurnally, having lower values in the daytime and higher values in the nighttime due to the diurnal change of temperature. However, $q$ increased steadily from $4 \mathrm{~g} \mathrm{~kg}^{-1}$ to approximately $7 \mathrm{~g} \mathrm{~kg}^{-1}$ during these four days (an obvious increasing trend of $R H$ was also observed), suggesting that air moisture accumulated during this period. This is a favorable condition for fog formation. The observed solar radiation $(S R)$ and the reference solar radiation $($ Ref_SR) are shown in Fig. 1 . The reference solar radiation was determined from the measured solar radiation on 9 November, when Nanjing was cloud-free and had relatively low $\mathrm{PM}_{2.5}$ $\left(<50 \mu \mathrm{g} \mathrm{m}^{-3}\right)$. The $S R$ curves were not smooth, indicating that there was intermittent cloud during the daytime during Period 1. At noon on 5 November, the maximum $S R$ was lower than $600 \mathrm{~W} \mathrm{~m}^{-2}$, which was lower than the values on 23 and 24 November. This may have been a result of the blocking effect of increased aerosols. The maximum CBLHs at 1400 LST decreased from about 1600 m (22 November) to about 1300 m (25 November), while the $\mathrm{PM}_{2.5}$ mass concentration increased.

Period 2, during which fog occurred, extended from 26 November to 1 December. As the fog occurred during the night of 26 November, the $R H$ remained high (>90\%), the $S R$ was blocked by the fog, and the CBLH was very low. At noon on 27 November, $q$ decreased to $4 \mathrm{~g} \mathrm{~kg}^{-1}$ (a relatively low level of air moisture), and $\mathrm{PM}_{2.5}$ mass concentration fell to about $50 \mu \mathrm{g} \mathrm{m}^{-3}$. The likely reason for these changes is that precipitation occurred during the night before and removed some water vapor and aerosols (wet deposition) from the near-surface atmosphere, although the precipitation was light. From 28 November, pollution reappeared and $\mathrm{PM}_{2.5}$ mass concentration began to increase. In the following days, the $\mathrm{PM}_{2.5}$ mass concentration increased rapidly to more than $200 \mu \mathrm{g} \mathrm{m}^{-3}$, and $q$ increased to $8 \mathrm{~g} \mathrm{~kg}^{-1}$. Fog continued to occur as the result of the accumulation 


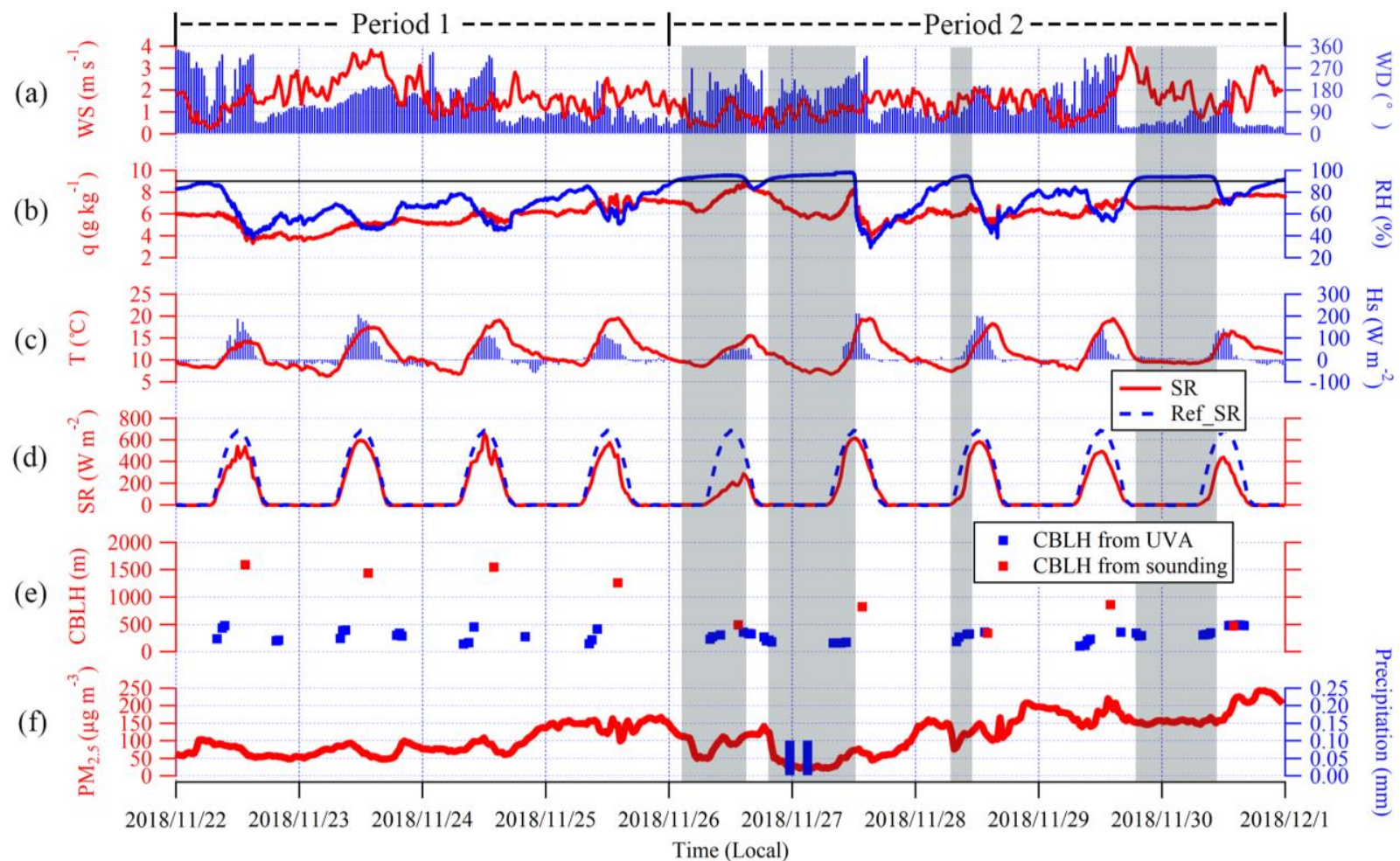

Fig. 1. Time series of (a) wind speed (WS) and wind direction $(W D)$, (b) specific humidity $(q)$ and relative humidity $(R H)$, (c) temperature $(T)$ and surface sensible heat flux $(H s)$, (d) solar radiation $(S R)$ and reference solar radiation (ref_SR), (e) CBLH, and (f) $\mathrm{PM}_{2.5}$ mass concentration and precipitation in the haze-fog event during 22-30 November, 2018. The periods of fog occurrence are shaded. 26-28 and 30 November are referred as the fog days, while 22-25 and 29 November are referred as the no-fog days.

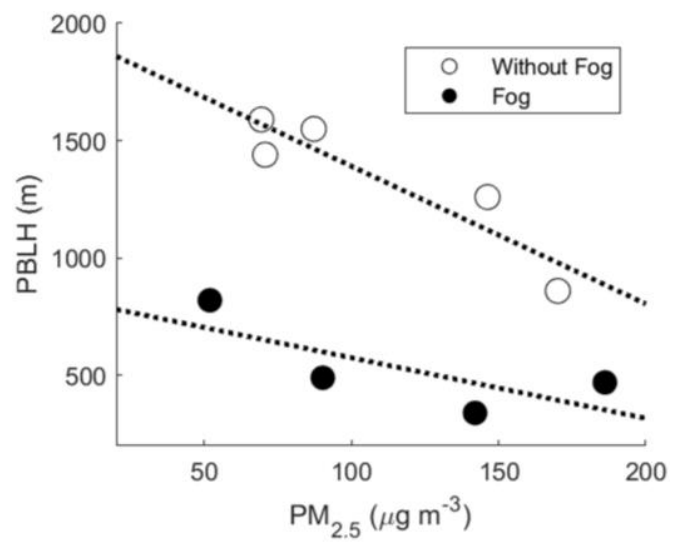

Fig. 2. Maximum CBLHs at 1400 LST on fog days (black dots) and no-fog days (circles) during 2230 November, 2018.

of air moisture. The maximum solar radiation decreased to $400 \mathrm{~W} \mathrm{~m}^{-2}$ on 30 November, which is about half the value of the Ref_SR, indicating that the "blocking effect" of the fog and pollution was strong. The maximum CBLHs at 1400 LST in the fog days were systematically lower than those in the no-fog days (Fig. 2). These results suggest that a lower CBLH is favorable for the accumulation of air pollutants, as well as air humidity, in the lower atmosphere.

\subsection{CBLHs on Fog and No-fog Days}

On 29 November, there was no fog before sunrise. Therefore, the CBLH developed immediately after sunrise, which is similar to the situation in Period 1 (no-fog days). Here, we attribute 29 
November as a no-fog day because there was no fog in the daytime and during the whole night before. However, on 26-28 and 30 November, fog persisted after sunrise (the fog began at sunrise on 28 November), and it is inevitable that the development of the CBLH was influenced by the fog in these days. We refer to these four days as fog days. Fig. 2 shows the maximum CBLH (at 1400 LST) on each day during 22-30 November, which is plotted against the daytime mean $\mathrm{PM}_{2.5}$ mass concentration. The maximum CBLHs on the no-fog days were significantly higher than those in the fog days, suggesting that development of the CBL was suppressed by fog. As shown in Fig. 1, the fog lasted into the later morning and even the afternoon, which possibly delayed the development of the CBL and consequently reduced the maximum CBLH. A lower CBLH is favorable for the accumulation of air pollutants in the $\mathrm{CBL}$, which can lead to heavy air pollution. From 27 to 30 November, the $\mathrm{PM}_{2.5}$ mass concentration accumulated and increased from $50 \mu \mathrm{g} \mathrm{m}^{-3}$ to more than $200 \mathrm{\mu g} \mathrm{m}^{-3}$ at the end of this haze-fog episode (Fig. 1(f)). Fig. 2 also shows that the maximum $\mathrm{CBLH}$ decreased with $\mathrm{PM}_{2.5}$ mass concentration at the surface on both no-fog and fog days. On the no-fog days, the shadowing effect of aerosols reduced the surface sensible heat flux and consequently deceased the CBLH (Barbaro et al., 2013; Zou et al., 2017). Our observational results of the maximum CBLH are consistent with the results of previous studies. However, the situation on the fog days seemed to be more complex. The development of the CBL forced by surface heating began after fog dissipation. On one hand, the maximum CBLH was influenced by the dissipation time of fog. When the fog dissipation was later in the morning, development of the $C B L$ was later and thus the maximum $C B L H$ was lower (if the fog did not last into the afternoon, as on 26 November, the CBL did not develop, and the CBLH was almost the same as the depth of the fog layer). On the other hand, it can be expected that the shadowing effect still functioned in the delayed development process of the $\mathrm{CBL}$, which may have decreased the maximum CBLH further. Our observational results on the fog days revealed a decreasing trend of maximum $\mathrm{CBLH}$ with increasing $\mathrm{PM}_{2.5}$ mass concentration, which seems to support this argument.

When neglecting large-scale synoptic forcing, daytime growth of the CBL is driven mainly by surface heating and upper-CBL entrainment (Stull, 1988; Sühring et al., 2014). In a simplified mixed-layer model, the CBLH can be predicted when the surface heat flux and the profile of potential temperature are known (Stull, 1988; van Zanten et al., 1999; Fedorovich et al., 2004; Sun, 2009). The growth rate of the CBLH can then be characterized by a simplified parameterization from Sun (2009), in which only the surface heat flux and the background stratification are needed. It is expressed as follows:

$\frac{d z_{i}}{d t}=\frac{1+A_{e}}{\beta} \cdot \frac{\overline{W^{\prime} \theta_{s}^{\prime}}}{\gamma z_{i}}$

where $z_{i}$ is the $\mathrm{CBLH}, A_{e}$ is the entrainment flux ratio (the ratio of the heat flux at the top of the CBL to that at the surface), which is a constant of approximately 0.2 (Deardorff et al., 1980), $\overline{W^{\prime} \theta^{\prime}{ }_{s}}$ is the surface kinematic heat flux, $\gamma$ is the lapse rate of potential temperature in the free atmosphere above the $\mathrm{CBL}$, and $\beta$ is a parameter that is a constant of approximately 0.9 for a purely buoyancy-driven CBL (Deardorff et al., 1980; Fedorovich et al., 2004; Sun, 2009). Eq. (1) shows that the growth rate of the CBLH is inversely proportional to the lapse rate of potential temperature in the free atmosphere above the $\mathrm{CBL}$. Therefore the profile of potential temperature plays an important role in the CBL development.

To understand the effects of haze and fog on the thermal structure of the $\mathrm{CBL}$, we compared the profiles of potential temperature at 0800 LST and 1400 LST on each day and the end of the fog period during 22-30 November, 2018. These profiles are plotted in Fig. 3. As shown in the upper panels, on the no-fog days at 0800 LST, the near-surface atmosphere became more stable when the $\mathrm{PM}_{2.5}$ mean mass concentration increased to a high level, whereas the profiles of potential temperature at 1400 LST presented a decreasing trend of maximum CBLH. This situation was more evident on 29 November, a heavy air pollution day, during which the lapse rate of potential temperature in the near-surface layer at 0800 LST was significantly larger and the CBLH at 1400 was significantly lower than those of the previous no-fog days. A larger lapse rate of potential temperature in the near-surface layer at 0800 LST means that after sunrise, the $\mathrm{CBL}$ develops in a more stably stratified background atmosphere and the growth rate of the CBLH 

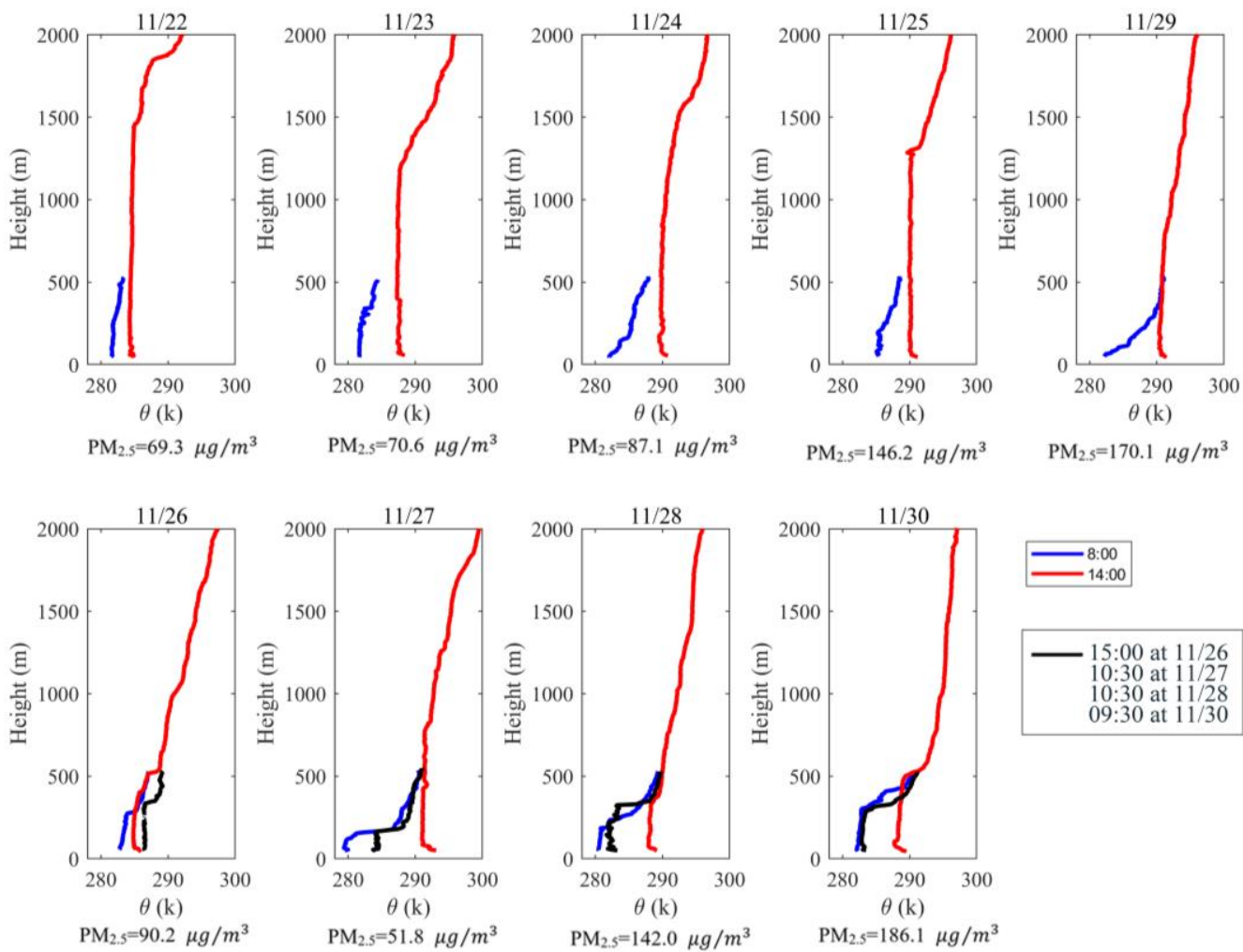

$\mathrm{PM}_{2.5}=170.1 \mu \mathrm{g} / \mathrm{m}^{3}$

Fig. 3. Profiles of potential temperature at 0800 LST (blue curves), 1400 LST (red curves) and the moment of fog dissipation (black curves) on the fog days (lower panels) and the no-fog days (upper panels) during 22-30 November. The fog dissipates at 1513 LST on 26 November, 1214 LST on 27 November, 1048 LST on 28 November, and 1027 LST on 30 November. The mean mass concentration of $\mathrm{PM}_{2.5}$ on each day is given below each panel.

is suppressed. The result that the near-surface atmosphere at the end of night becomes more stable on a heavier air pollution day is consistent with the long-term observations presented in Zou et al. (2017). Therefore, air pollution can impact the CBLH by different processes. On one hand, a high level of aerosol loading in the PBL allows the formation of a more stable nocturnal PBL, which suppresses the growth rate of the PBLH in the morning. On the other hand, high $\mathrm{PM}_{2.5}$ mass concentration increases the shadowing effect of aerosols on solar radiation and reduces the surface sensible heat flux, which leads to a lower CBLH. The heating effect of aerosols also influences the development of the CBL. The absorbing aerosols induce solar heating in the atmosphere, and the heating effect is stronger in the upper part of the CBL (Barbaro et al., 2013; Ding et al., 2016b). To the best of our knowledge, the stabilized upper part of the CBL can suppress the overshooting of thermals and weaken the entrainment process, which means that the entrainment flux ratio $A_{e}$ is reduced. According to Eq. (1), a smaller $A_{e}$ leads to a smaller growth rate of the CBLH.

The lower panels in Fig. 3 show profiles of potential temperature at different times on the fog days. 26 November is somewhat special because the fog lasted into the afternoon and dissipated at about 1530 LST. When the fog dissipated, the potential temperature profile (the black line) showed that the CBLH was about $350 \mathrm{~m}$. At 1400 LST, the potential temperature profile from radiosonde (the red line) indicates that the $\mathrm{CBLH}$ was $400 \mathrm{~m}$ (we choose the middle height of the lowest inversion layer as the $\mathrm{CBLH}$, when the potential temperature profile revealed more than one inversion layer). Fig. 1 shows the time series of the CBLH on that day. The CBLH is actually simply the depth of the fog layer during the fog period. Because the fog dissipated in the afternoon, the CBLH decreased slightly over the rest of the day. Therefore, the depth of the fog layer determined the CBLH on that day. On 27 November, the profile at 0800 LST (the blue line) showed a large potential temperature jump at the height of about $150 \mathrm{~m}$, the height of the top of the fog layer. At about 1200 LST, the fog dissipated, but the potential temperature jump at 
that height still existed. The fog layer depth was shallow and the potential temperature jump became lower at this moment. Additionally, the surface sensible heat flux increased rapidly to about $200 \mathrm{~W} \mathrm{~m}^{-3}$ after fog dissipation (Fig. 1). Thus, in the following time, the surface heating was relatively strong, and the potential temperature jump could be consumed easily. The potential temperature profile (the red line) shows that at 1400 LST the CBLH reached a relatively high altitude of about $800 \mathrm{~m}$. A similar situation occurred on 28 and 30 November. On these two days, at 0800 LST, there was a strong capping inversion layer above the fog layer, and at the time of fog dissipation, a step-like potential temperature jump still existed at the top of the fog layer. Because the fog layer depth (about $350 \mathrm{~m}$ ) on these two days was thicker than that on 27 November, consumption of the potential temperature jump at the top of the fog layer was more difficult. The CBLH remained unchanged until the potential temperature jump was consumed. This situation is similar to that in many large-eddy simulation studies of the $\mathrm{CBL}$, in which a large potential temperature jump is set at a chosen height so that the top of the mixed layer is approximately fixed during the simulation. To our knowledge, Eq. (1) is not suitable for this situation because the potential temperature jump cuts off the interaction between the mixed layer and the free atmosphere. Here, we distinguish the potential temperature jump from the potential temperature difference across the entrainment zone for a CBL that is developing in the equilibrium state. The former corresponds to a step-like shaped potential temperature profile, but the latter corresponds to a smoothly curved potential temperature profile. Therefore, Eq. (1) is only applicable when the CBL reaches an equilibrium state, in which the interaction between the mixed layer and the free atmosphere forms a stable interfacial layer, i.e., the entrainment zone, or the so-called capping inversion layer.

The potential temperature profile at 1400 LST on 28 November shows that the step-like shape of the profile disappeared but the CBLH changed very little, suggesting that the potential temperature jump was consumed just before this time. The potential temperature profile at 1400 LST on 30 November shows that the CBLH increased only about $150 \mathrm{~m}$ from the moment of fog dissipation, implying that most of the time between 1030 LST and 1400 LST was used to consume the potential temperature jump. Therefore, our observations indicate that the potential temperature jump formed at the top of the fog layer delays CBL development after fog dissipation because a certain amount of time is needed for surface heating to increase the air temperature in the whole mixed layer so that the potential temperature jump can be eliminated and then the $\mathrm{CBL}$ begins to develop. This raises the question of why a potential temperature jump can form at the top of the fog. The primary mechanism for the observed vertical temperature structure is likely cloud top cooling (Koračin et al., 2005; Guo et al., 2020; Zhang et al., 2020). When the fog becomes optically thick enough, there is greater radiative flux divergence near the top of the fog than the bottom. At this point, longwave radiative cooling occurring at the fog top generates cold thermals that sink and begin to convectively mix the fog layer. The fog becomes more uniform in the vertical with a well-defined top edge. And this sharp top concentrates the radiative divergence closer to that region, which reinforces vertical mixing in the fog layer (Stull, 1988). Therefore, the well-mixed fog appears uniform in the vertical direction and has a well-defined top edge, which forms a sharp potential temperature jump at the top of the fog layer. Our observations show that the step-like jump corresponds to 3-5 $\mathrm{K}$ temperature increase over a thin layer with a depth of only about $20 \mathrm{~m}$. Such a large lapse rate cannot be resolved by weather and climate models, and the growth rate of the CBLH after fog dissipation may be overestimated.

To determine the exact strength of the potential temperature jump at the top of the fog layer, we calculated the lapse rate in the thin layer with a depth of $20 \mathrm{~m}$ from each temperature profile measured by UAV. The results are shown in Fig. 4 and are denoted by green stars. On 26 November, the potential temperature jump was relatively small (as shown in Fig. 3), but the value of the lapse rate at the top of the fog layer was larger than $50 \mathrm{~K} \mathrm{~km}^{-1}$ and could reach $100 \mathrm{~K} \mathrm{~km}^{-1}$. In the subsequent three fog days, the potential temperature jump was relatively strong, and the lapse rate at the top of the fog layer was typically larger than $100 \mathrm{~K} \mathrm{~km}^{-1}$ and could reach $250 \mathrm{~K} \mathrm{~km}^{-1}$. Observations showed that a very strong stable layer formed in a thin layer at the fog top, although the lapse rate in this layer varies with time and the mean strength was different in different cases. In high-resolution numerical models, the vertical grid distance is about $100 \mathrm{~m}$. To determine the strength of stratification in a layer with a depth of $100 \mathrm{~m}$ at the fog layer top, we also calculated the mean lapse rate of potential temperature in this layer. The results are plotted as blue stars 


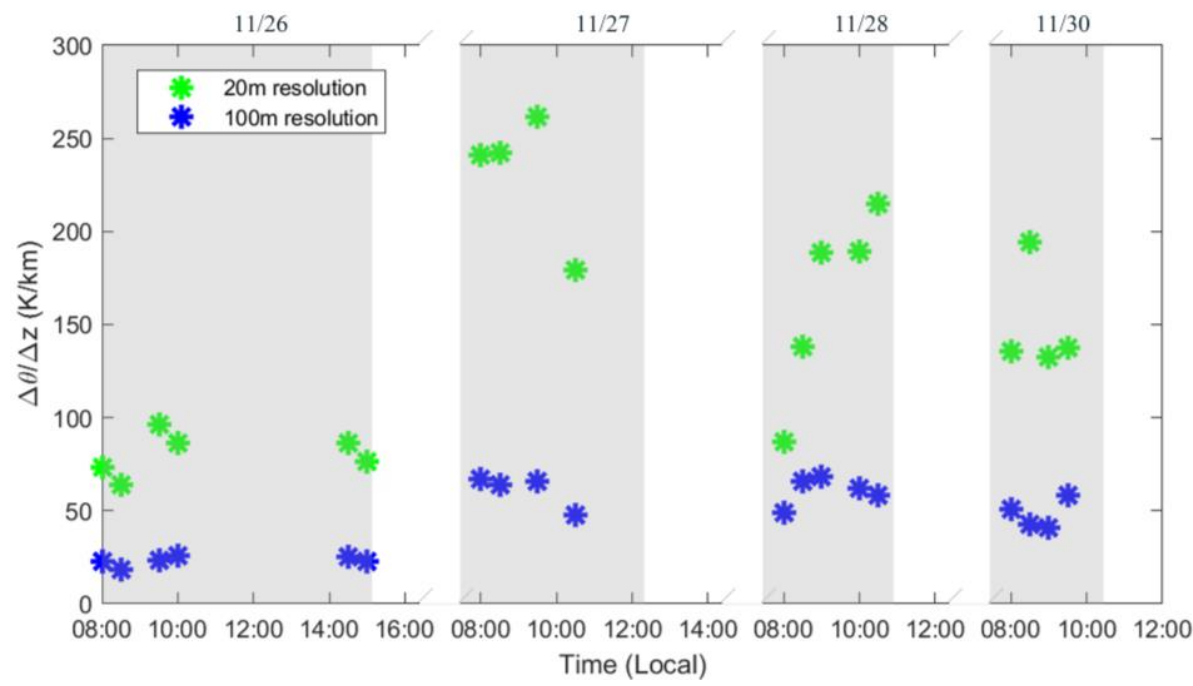

Fig. 4. Mean lapse rate of potential temperature at the fog layer top in each temperature profile measured by UAV. The shaded areas represent the daytime duration of fog. The green stars denote the lapse rate in the layer with a depth of $20 \mathrm{~m}$, and the blue stars denote the lapse rate in the layer at a depth of $100 \mathrm{~m}$.

in Fig. 4. On 26 November, the lapse rate is about $25 \mathrm{~K} \mathrm{~km}^{-1}$, but it is about $50 \mathrm{~K} \mathrm{~km}^{-1}$ on the following three fog days. This large lapse rate is maintained until the end of the fog period. This means that the CBL develops in a much more stably stratified background atmosphere after fog dissipation and that the growth rate of the CBLH is significantly suppressed. In this situation, the overshooting of rising thermals from the mixed layer is inhibited by the strongly stabilized layer above the top of the mixed layer, which eliminates entrainment. Therefore, we can use the encroachment model (Boers et al. 1984) to estimate CBLH growth rate. The model can be described as $d z_{i} / d t=\overline{W^{\prime} \theta^{\prime}{ }_{s}} /\left(\Gamma z_{i}\right)$, where $\Gamma$ is the lapse rate of potential temperature immediately above the mixed layer. This model neglects entrainment, implying that the mixed layer top erodes into the strongly stable layer due to the increased air temperature in the mixed layer. Assuming that $\Gamma=50 \mathrm{~K} \mathrm{~km}^{-1}$ (considering the situation in the later three fog days), $\overline{W^{\prime} \theta^{\prime}}$ s $=0.15 \mathrm{~K} \mathrm{~m} \mathrm{~s}^{-1}$ (the corresponding surface heat flux is $180 \mathrm{~W} \mathrm{~m}^{-2}$, which was estimated according to our measurements at noontime), and with an initial CBLH of $350 \mathrm{~m}$ at 1030 LST (according to observed fog layer depth), the calculation showed that about $3.7 \mathrm{~h}$ is required for the CBLH to increase to $450 \mathrm{~m}$. This estimation agrees with the observations in the latter two fog days. Our observations on 28 and 30 November indicated that about $3.5 \mathrm{~h}$ is required for the mixed layer top to penetrate this stable layer. Therefore, fog can significantly suppress the CBL development by inducing a strongly stabilized layer at the top of the fog layer.

\subsection{Vertical Distribution of $\mathrm{PM}_{2.5}$ during Fog Days}

Fog droplets interact with aerosol particles and soluble gases in the atmosphere. Thus, fogs can affect pollutant formation, transformation, and removal. In this study, we observed the vertical distribution of $\mathrm{PM}_{2.5}$ mass concentration in the lower atmosphere both during fog periods and after fog dissipation. Fig. 5 shows profiles of $\mathrm{PM}_{2.5}$ mass concentration and relative humidity at different times during the fog days. On 26 November, the profiles of relative humidity at 0830 LST and 1000 LST revealed that the fog layer top reached about $300 \mathrm{~m}$ AGL. Meanwhile, the profiles of $\mathrm{PM}_{2.5}$ mass concentration at the two times showed that in the upper part of the fog layer, the $\mathrm{PM}_{2.5}$ mass concentration in the atmosphere was very small (only about $25 \mu \mathrm{g} \mathrm{m}^{-3}$ ), although it increased with proximity to ground level. However, at 1430 LST, the profiles show that the $\mathrm{PM}_{2.5}$ mass concentration in the fog layer increased to about $100 \mu \mathrm{g} \mathrm{m}^{-3}$ while the relative humidity in this layer decreased to about $90 \%$, suggesting that the fog still existed at this time but that the evaporation of fog droplets released a lot of $\mathrm{PM}_{2.5}$ back to the atmosphere. At 1530 LST, the fog dissipated, evaporation ended, and the $\mathrm{PM}_{2.5}$ mass concentration increased 

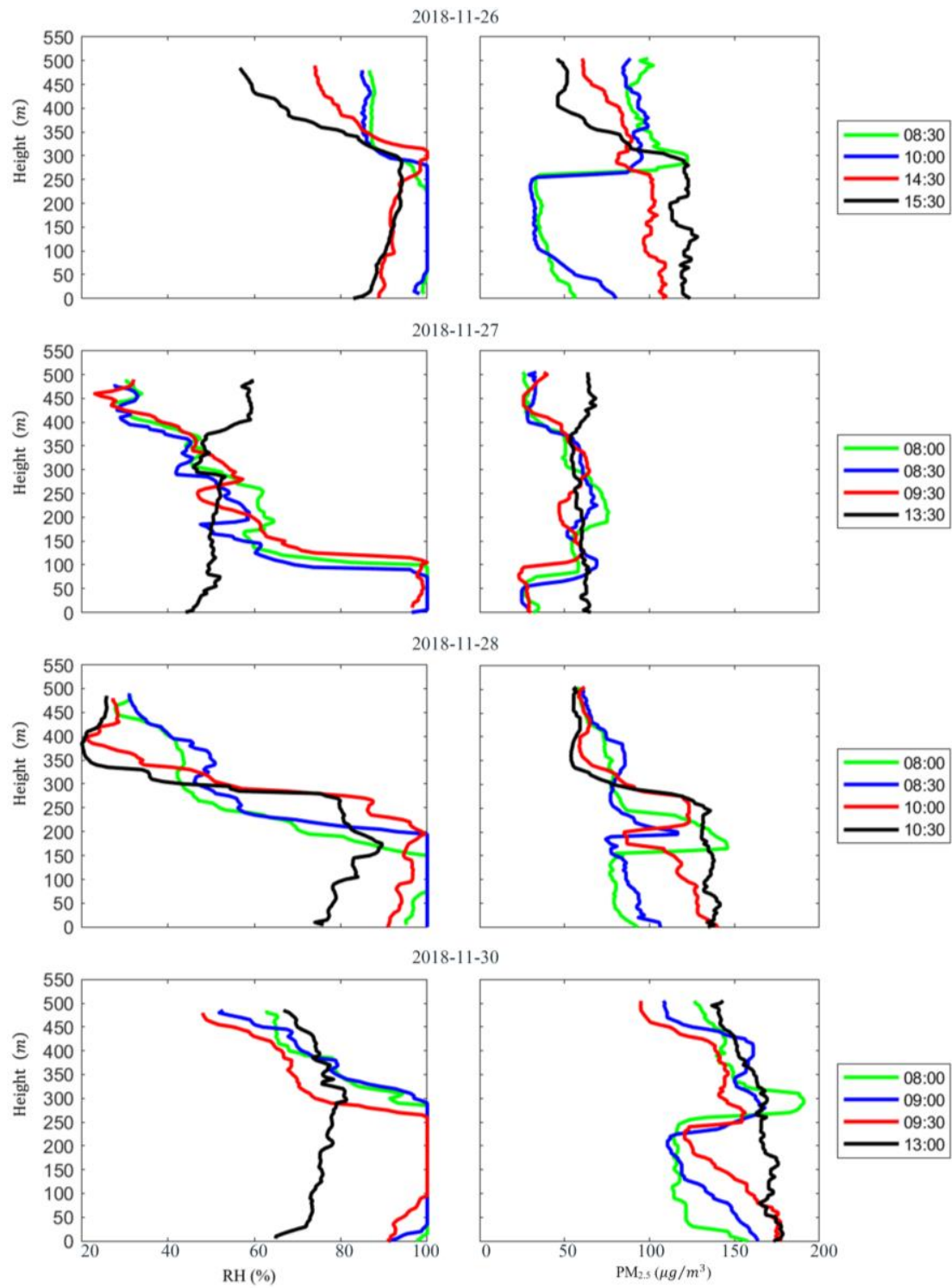

Fig. 5. Vertical profile of relative humidity (left) and PM2.5 mass concentration (right) for the fog days. The different colors represent different measurement times. The fog dissipates at 1513 LST on 26 November, 1214 LST on 27 November, 1048 LST on 28 November, and 1027 LST on 30 November.

further to about $120 \mathrm{\mu g} \mathrm{m}^{-3}$, which is almost the same as the level before fog formation, implying that almost all of the $\mathrm{PM}_{2.5}$ in the fog droplets was returned to the atmosphere. Fig. 5 shows that the same process repeated in the following fog days. We note that on 27 November, at the time of fog dissipation, the $\mathrm{PM}_{2.5}$ mass concentration was reduced to a lower level in comparison with the value before fog formation, which was evidently the result of the light precipitation that occurred during the fog period (Fig. 1). However, on the no-precipitation fog days, the $\mathrm{PM}_{2.5}$ mass concentration at the time of fog dissipation returned to the level before fog formation. The scavenging effect of fog can significantly reduce the aerosol concentration in the atmosphere (Niu et al., 2010b; Han et al., 2018). Our observations suggest that the wet deposition effect of fog on $\mathrm{PM}_{2.5}$ is negligible unless precipitation occurs during the fog period. This means that the wet scavenging effect of fog on aerosols only occurs during a fog period. Once the fog dissipates, the aerosols return to the atmosphere from the fog droplets. The fog droplets provide a liquid phase reaction environment for $\mathrm{PM}_{2.5}$ with different chemical compositions and soluble gases. However, this problem is beyond the scope of this study. We will investigate this problem based on observations in a future research. 
A severe haze-fog event occurred in the YRD region, eastern China, during 22-30 November, 2018. In this study, we focused on the interactions among haze, fog, and atmospheric boundary layer during the haze-fog episode based on observations at the SORPES site in Nanjing, which is located in the northeastern part of the YRD region. The observations showed that the PM 2.5 mass concentration increased from about $50 \mathrm{\mu g} \mathrm{m}^{-3}$ to more than $200 \mu \mathrm{g} \mathrm{m}^{-3}$ during this period, while the maximum CBLH decreased from about 1500 to $500 \mathrm{~m}$ or even lower. During Period 1 (22-26 November), i.e., on the no-fog days, $\mathrm{PM}_{2.5}$ accumulated due to lower wind speed, and increased air humidity. During Period 2 (26-30 November), fog occurred almost every day, the PM 2.5 mass concentration increased, and the maximum CBLHs on the fog days were significantly lower than those on the no-fog days. These observational results suggest that the interactions among haze, fog and atmospheric boundary layer enhance air pollution. On one hand, the increase of aerosol loading reduces the CBLH by decreasing the daytime surface heating and stabilizing the atmospheric boundary layer, and the aerosol-induced reduction of the CBLH limits the aerosols and air moisture to a smaller space and results in higher $\mathrm{PM}_{2.5}$ mass concentration and air humidity. This is a well-known interaction process on the no-fog days. On the other hand, increased aerosol loading and air humidity provide favorable conditions for fog formation, and the CBLH significantly reduces after fog dissipation, which can further increase $\mathrm{PM}_{2.5}$ mass concentration and lead to heavy air pollution.

Observations showed that the maximum CBLHs on the fog days were much lower than those on the no-fog days, suggesting that the occurrence of fog significantly suppressed the development of the CBL. The CBL develops after sunrise on no-fog days but develops after fog dissipation on fog days. Therefore, fog delays the development of the CBL. However, the existence of fog results in a step-like potential temperature jump at the top of the fog layer because of longwave radiative cooling and maintains it until the time of fog dissipation. Thereafter, the CBL first increases the air temperature in the mixed layer by surface heating for a few hours to eliminate the step-like potential temperature jump. Then, it develops freely in the equilibrium state. This process further delays the development of the CBL, which leads to a much lower CBLH and consequently, a high level of $\mathrm{PM}_{2.5}$ mass concentration on fog days.

Observations also showed that the wet deposition effect of fog on $\mathrm{PM}_{2.5}$ is negligible if the fog cannot form precipitation. Previous studies pointed out that the scavenging effect of fog can significantly reduce aerosol concentration in the atmosphere. Our observations suggest that this effect only occurs during the fog period. When the fog dissipates, the aerosols are returned to the atmosphere from the fog droplets. Along with the effect of fog on the thermal structure of the $\mathrm{CBL}$, which can significantly reduce the $\mathrm{CBLH}$, fog plays an important role in the occurrence of heavy air pollution in moist areas, such as the YRD region, eastern China.

\section{ACKNOWLEDGEMENTS}

The work was supported by the Ministry of Science and Technology of China (2016YFC0200500) and National Natural Science Foundation of China (91544231).

\section{REFERENCES}

Banta, R.M., Senff, C.J., White, A.B., Trainer, M., McNider, R.T., Valente, R.J., Mayor, S.D., Alvarez, R.J., Hardesty, R.M., Parrish, D., Fechsenfeld, F.C. (1998). Daytime buildup and nighttime transport of urban ozone in the boundary layer during a stagnation episode. J. Geophys. Res. 103, 22519-22544. https://doi.org/10.1029/98jd01020

Barbaro, E., Vilà-Guerau de Arellano, J., Krol, M.C., Holtslag, A.A.M. (2013). Impacts of aerosol shortwave radiation absorption on the dynamics of an idealized convective atmospheric boundary layer. Boundary Layer Meteorol. 148, 31-49. https://doi.org/10.1007/s10546-0139800-7

Barkjohn, K.K., Bergin, M.H., Norris, C., Schauer, J.J., Zhang, Y., Black, M., Hu, M., Zhang, J. (2020). 
Using low-cost sensors to quantify the effects of air filtration on indoor and personal exposure relevant $\mathrm{PM}_{2.5}$ concentrations in Beijing, China. Aerosol Air Qual. Res. 20, 297-313. https://doi.org/10.4209/aaqr.2018.11.0394

Batchavarova, E., Gryning, S.E. (1991). Applied model for the growth of the daytime mixed layer. Boundary Layer Meteorol. 56, 261-274. https://doi.org/10.1007/bf00120423

Boers, R., Eloranta, E.W., Coulter, R.L. (1984). Lidar observations of mixed layer dynamics: Tests of parameterized entrainment models of mixed layer growth rate. J. Climate Appl. Meteor. 23, 247-266. https://doi.org/10.1175/1520-0450(1984)023<0247:LOOMLD>2.0.CO;2

Chan, C.K., Yao, X. (2008). Air pollution in mega cities in China. Atmos. Environ. 42, 1-42. https://doi.org/10.1016/j.atmosenv.2007.09.003

Chen, F., Zhang, X., Zhu, X., Zhang, H., Gao, J., Hopke, P.K. (2017). Chemical characteristics of $\mathrm{PM}_{2.5}$ during a 2016 winter haze episode in Shijiazhuang, China. Aerosol Air Qual. Res. 17, 368380. https://doi.org/10.4209/aaqr.2016.06.0274

Dall'Osto, M., Harrison, R.M., Coe, H., Williams, P. (2009). Real-time secondary aerosol formation during a fog event in London. Atmos. Chem. Phys. 9, 2459-2469. https://doi.org/10.5194/acp9-2459-2009

Deardorff, J.W., Willis, G.E., Stockton, B.H. (1980). Laboratory studies of the entrainment zone of a convectively mixed layer. J. Fluid. Mech. 100, 41-64. https://doi.org/10.1017/S0022112080 001000

Ding, A.J., Fu, C.B., Yang, X.Q., Sun, J.N., Zheng, L.F., Xie, Y.N., Herrmann, E., Nie, W., Petäjä, T., Kerminen, V.M., Kulmala, M. (2013a). Ozone and fine particle in the western Yangtze River Delta: an overview of $1 \mathrm{yr}$ data at the SORPES station. Atmos. Chem. Phys. 13, 5813-5830. https://doi.org/10.5194/acp-13-5813-2013

Ding, A.J., Fu, C.B., Yang, X.Q., Sun, J.N., Petäjä, T., Kerminen, V.M., Wang, T., Xie, Y., Herrmann, E. Zheng, L.F., Nie, W., Liu, Q., Wei, X.L., Kulmala, M. (2013b). Intense atmospheric pollution modifies weather: A case of mixed biomass burning with fossil fuel combustion pollution in eastern China. Atmos. Chem. Phys. 13, 10545-10554. https://doi.org/10.5194/acp-13-10545-2013

Ding, A., Nie, W., Huang, X., Chi, X., Sun, J., Kerminen, V. M., Xu, Z., Guo, W., Petäjä, T., Yang, X., Kulmala, M., Fu, C. (2016a). Long-term observation of air pollution-weather/climate interactions at the SORPES station: A review and outlook. Front. Environ. Sci. Eng. 10, 15. https://doi.org/10.1007/s11783-016-0877-3

Ding, A.J., Huang, X., Nie, W., Sun, J.N., Kerminen, V.M., Petäjä, T., Su, H., Cheng, Y.F., Yang, X. Q., Wang, M.H., Chi, X.G., Wang, J.P., Virkkula, A., Guo, W.D., Yuan, J., Wang, S.Y., Zhang, R.J., Wu, Y.F., Song, Y., Zhu, T., Zilitinkevich, S., Kulmala, M., Fu, C.B. (2016b). Enhanced haze pollution by black carbon in megacities in China. Geophys. Res. Lett. 43, 2873-2879. https://doi.org/10. 1002/2016GL067745

Ding, Q., Sun, J., Huang, X., Ding, A., Zou, J., Yang, X., Fu, C. (2019). Impacts of black carbon on the formation of advection-radiation fog during a haze pollution episode in eastern China. Atmos. Chem. Phys. 19, 7759-7774. https://doi.org/10.5194/acp-19-7759-2019

Doyle, M., Dorling, S. (2001). Visibility trends in the UK 1950-1997. Atmos. Environ. 36, 31613172. https://doi.org/10.1016/S1352-2310(02)00248-0

Fedorovich, E., Conzemius, R., Mironov, D. (2004). Convective entrainment into a shear-free, linearly stratified atmosphere: bulk models reevaluated through large eddy simulations. J. Atmos. Sci. 61, 281-295. https://doi.org/10.1175/1520-0469(2004)061<0281:CEIASL>2.0.CO;2

Fiore, A.M., Jacob, D.J., Bey, I., Yantosca, R.M., Field, B.D., and Fusco, A.C. (2002). Background ozone over the United States in summer: Origin, trend, and contribution to pollution episodes J. Geophys. Res. 107. https://doi.org/10.1029/2001JD000982

Gao, Y., Zhang, M., Liu, Z., Wang, L., Wang, P., Xia, X., Tao, M., Zhu, L. (2015). Modeling the feedback between aerosol and meteorological variables in the atmospheric boundary layer during a severe fog-haze event over the North China Plain. Atmos. Chem. Phys. 15, 4279-4295. https://doi.org/10.5194/acp-15-4279-2015

Graedel, T.E., Weschler, C.J., Mandich, M.L. (1985). Influence of transition metal complexes on atmospheric droplet acidity. Nature 317, 240-242. https://doi.org/10.1038/317240a0

Gray, E., Gilardoni, S., Baldocchi, D., McDonald, B.C., Facchini, M.C., Goldstein, A.H. (2019). Impact of air pollution controls on radiation fog frequency in the Central Valley of California. J. Geophys. Res. 124, 5889-5905. https://doi.org/10.1029/2018jd029419 
Guo, S., Hu, M., Zamora, M. L., Peng, J., Shang, D., Zheng, J., Du, Z., Wu, Z., Shao, M., Zeng, L., Molina, M.J., Zhang, R. (2014). Elucidating severe urban haze formation in China. Proc. Natl. Acad. Sci. U.S.A. 111, 17373-17378. https://doi.org/10.1073/pnas.1419604111

Guo, Z., Wang, M., Larson, V.E., Zhou, T. (2019). A cloud top radiative cooling model coupled with CLUBB in the Community Atmosphere Model: Description and simulation of low clouds. J. Adv. Model. Earth Syst. 11, 979-997. https:/.1029/2018MS001505

Han, S., Liu, J. L., Hao, T., Zhang, Y., Li, P., Yang, J., Wang, Q., Cai, Z., Yao, Q., Zhang, M., Wang, X.J. (2018). Boundary layer structure and scavenging effect during a typical winter haze-fog episode in a core city of BTH region, China. Atmos. Environ. 179, 187-200. https://doi.org/10. 1016/j.atmosenv.2018.02.023

He, G.X., Yu, C.W.F., Lu, C., Deng, Q.H. (2013). The Influence of synoptic pattern and atmospheric boundary layer on $\mathrm{PM}_{10}$ and urban heat island. Indoor Built Environ. 22, 796-807. https://doi.org/10.1177/1420326X13503576

He, K.B., Huo, H., Zhang, Q. (2002). Urban air pollution in China: Current status, characterizes and progress. Annu. Rev. Energy Env. 27, 397-431. https://doi.org/10.1146/annurev.energy.27.12 2001.083421

Hennemuth, B., Lammert, A. (2006). Determination of the atmospheric boundary layer height from radiosonde and lidar backscatter. Boundary Layer Meteorol. 120, 181-200. https://doi.org/10.1007/s10546-005-9035-3

Huang, R.J., Zhang, Y., Bozzetti, C., Ho, K. F., Cao, J.J., Han, Y., Daellenbach, K.R., Slowik, J.G., Platt, S.M., Canonaco, F., Zotter, P., Wolf, R., Pieber, S.M., Bruns, E.A., Crippa, M., Ciarelli, G., Piazzalunga, A., Schwikowski, M., Abbaszade, G., ... Prévôt, A.S.H. (2014). High secondary aerosol contribution to particulate pollution during haze events in China. Nature 514, 218-222. https://doi.org/10.1038/nature13774

Huang, X., Ding, A., Liu, L., Liu, Q., Ding, K., Niu, X., Nie, W., Xu, Z., Chi, X., Wang, M., Sun, J., Guo, W., Fu, C. (2016). Effects of aerosol-radiation interaction on precipitation during biomassburning season in East China. Atmos. Chem. Phys. 16, 10063-10082. https://doi.org/10.5194/ acp-16-10063-2016

Karle, N.N., Mahmud, S., Sakai, R.K., Fitzgerald, R.M., Morris, V.R., Stockwell, W.R. (2020). Investigation of the successive ozone episodes in the El Paso-Juarez region in the summer of 2017. Atmosphere 11, 532. https://doi.org/10.3390/atmos11050532

Koračin, D., Businger, J.A., Dorman, C.E., Lewis, J.M. (2005). Formation, evolution, and dissipation of coastal sea fog. Boundary Layer Meteorol. 117, 447-478. https://doi.org/10.1007/s10546005-2772-5

Kulmala, M., Laaksonen, A., Charlson, R.J., Korhonen, P. (1997). Clouds without supersaturation. Nature 388, 336-337. https://doi.org/10.1038/41000

Lin, C., Zhang, Z., Zhao, P.U., Wang, F. (2017). Numerical simulations of an advection fog event over Shanghai Pudong international air-port with the WRF model. J. Meteorolog. Res. 31, 874889. https://doi.org/10.1007/s13351-017-6187-2

Liu, N., Zhou, S., Liu, C., Guo, J. (2019). Synoptic circulation pattern and boundary layer structure associated with $\mathrm{PM}_{2.5}$ during wintertime haze pollution episodes in Shanghai. Atmos. Res. 228 186-195. https://doi.org/10.1016/j.atmosres.2019.06.001

Ma, Q., Wu, Y., Tao, J., Xia, Y., Liu, X., Zhang, D., Han, Z., Zhang, X., Zhang, R. (2017). Variations of chemical composition and source apportionment of $\mathrm{PM}_{2.5}$ during winter haze episodes in Beijing. Aerosol Air Qual. Res. 17, 2791-2803. https://doi.org/10.4209/aaqr.2017.10.0366

Mohan, M., Payra, S. (2009). Influence of aerosol spectrum and air pollutants on fog formation in urban environment of megacity Delhi, India. Environ. Monit. Assess. 151, 265-277. https://doi.org/10.1007/s10661-008-0268-8

Niu, F., Li, Z., Li, C., Lee, K.H., Wang, M. (2010a). Increase of wintertime fog in China: Potential impacts of weakening of the Eastern Asian monsoon circulation and increasing aerosol loading. J. Geophys. Res. 115, D00K20. https://doi.org/10.1029/2009JD013484

Niu, S., Lu, C., Yu, H., Zhao, L., Lu, J. (2010b). Fog research in China: an overview. Adv. Atmos. Sci. 27, 639-662. https://doi.org/10.1007/s00376-009-8174-8

Nordbo, A., Järvi, L., Haapanala, S., Moilanen, J., Vesala, T. (2013). Intra-city variation in urban morphology and turbulence structure in Helsinki, Finland. Boundary Layer Meteorol. 146, 469496. https://doi.org/10.1007/s10546-012-9773-y 
Sachweh, M., Koepke, P. (1995). Radiation fog and urban climate. Geophys. Res. Lett. 22, 10731076. https://doi.org/10.1029/95GL00907

Schichtel, B.A., Husar, R.B., Falke, S.R., Wilson, W.E. (2001). Haze trends over the United States, 1980-1995. Atmos. Environ. 35, 5205-5210. https://doi.org/10.1016/S1352-2310(01)00317-X

Schotanus, P., Nieuwstadt, F.T.M., Bruin, H.A.R.D. (1983). Temperature measurement with a sonic anemometer and its application to heat and moisture fluxes. Boundary Layer Meteorol. 26, 81-93. https://doi.org/10.1007/BF00164332

Seibert, P., Beyrich, F., Gryning, S.E., Joffre, S., Rasmussen, A., Tercier, P. (2000). Review and intercomparison of operational methods for the determination of the mixing height. Atmos. Environ. 34, 1001-1027. https://doi.org/10.1016/S1352-2310(99)00349-0

Shi, C., Yang, J., Qiu, M., Hao, Z., Su, Z., Li, Z. (2010). Analysis of an extremely dense regional fog event in Eastern China using a mesoscale model. Atmos. Res. 95, 428-440. https://doi.org/10. 1016/j.atmosres.2009.11.006

Stull, R.B. (1988). An introduction to boundary layer meteorology, Kluwer Academic Publishers, Springer, Dordrecht. https://doi.org/10.1007/978-94-009-3027-8

Sühring, M., Maronga, B., Herbort, F., Raasch, S. (2014). On the effect of surface heat-flux heterogeneities on the mixed-layer-top entrainment. Boundary Layer Meteorol. 151, 531-556. https://doi.org/10.1007/s10546-014-9913-7

Sun, J. (2009). On the parameterization of convective entrainment: Inherent relationships among entrainment parameters in bulk models. Adv. Atmos. Sci. 26, 1005-1014. https://doi.org/10.1 007/s00376-009-7222-8

Tie, X., Cao, J. (2009). Aerosol pollution in China: Present and future impact on environment. Particuology. 7, 426-431. https://doi.org/10.1016/j.partic.2009.09.003

van Zanten, M.C., Duynkerke, P.G., Cuijpers, J.W.M. (1999). Entrainment parameterization in convective boundary layers. J. Atmos. Sci. 56, 813-828. https://doi.org/10.1175/15200469(1999)056<0813:EPICBL>2.0.CO;2

VanReken, T.M., Dhammapala R.S., Jobson, B.T., Bottenus, C.L., VanderSchelden, G.S., Kaspari, S.D., Gao, Z., Zhu, Q., Lamb, B.K., Liu, H., Johnston, J. (2017). Role of persistent low-level clouds in mitigating air quality impacts of wintertime cold pool conditions. Atmos. Environ. 154, 236246. https://doi.org/10.1016/j.atmosenv.2017.01.043

Wang, J., Wang, S., Jiang, J., Ding, A., Mei, Z., Zhao, B., Wong, D.C., Zhou, W., Zheng, G., Wang, L. (2014). Impact of aerosol=meteorology interactions on fine particle pollution during China's severe haze episode in January 2013. Environ. Res. Lett. 9, 094002. https://doi.org/10.1088/17 48-9326/9/9/094002

Zhang, J., Zheng, Y., Li, Z., Xia, X., Chen, H. (2020). A 17-year climatology of temperature inversions above clouds over the ARM SGP site: The roles of cloud radiative effects. Atmos. Res. 237, 104810. https://doi.org/10.1016/j.atmosres.2019.104810

Zhang, R., Li, Q., Zhang, R. (2014). Meteorological conditions for the persistent severe fog and haze event over eastern China in January 2013. Sci. China-Earth Sci. 57, 26-35. https://doi.org/10.1007/s11430-013-4774-3

Zhao, D., Chen, H., Sun, X., Shi, Z. (2018). Spatio-temporal variation of $\mathrm{PM}_{2.5}$ pollution and its relationship with meteorology among five megacities in China. Aerosol Air Qual. Res. 18, 23182331. https://doi.org/10.4209/aaqr.2017.09.0351

Zou, J., Sun, J., Ding, A., Wang, M., Guo, W., Fu, C. (2017). Observation-based estimation of aerosol-induced reduction of planetary boundary layer height. Adv. Atmos. Sci. 34, 1057-1068. https://doi.org/10.1007/s00376-016-6259-8 